\title{
Социальное признание как фактор формирования профессионального имиджа учителя
}

\author{
Шаруева Е.В. \\ Самарский филиал Московского городского педагогического университета, \\ Россия, 443081, г. Самара, ул. Стара Загора, 76 \\ E-mail: eb3011@mail.ru
}

\begin{abstract}
Аннотация. В настоящее время система образования предъявляет новые требования не только к профессиональной деятельности современного учителя, которые не только направлены на модернизацию профессиональной деятельности педагога, но и вносят качественные изменения в его профессиональный статус. Таким образом возникает противоречие между потребностью государства в повышении статуса учителя и ограниченными социальными возможностями формирования его положительного профессионального имиджа. Несмотря на большое количество публикаций по данной тематике, социальное признание как фактор его формирования не был достаточно изучен. Цель данного исследования - подтвердить гипотезу: ведущим социальным фактором, оказывающим значительное влияние на формирование профессионального имиджа учителя и отражающее его социальный статус, выступает социальное признание его педагогической деятельности участниками образовательных отношений. Исследование проводилось на основе контент-анализа нормативно-правовых документов, регламентирующих профессиональную деятельность учителя, и анализа педагогического состава Самарской области. В результате исследования были выявлены уровни и виды социального признания представителя педагогической профессии, направленные на повышения статуса учителя и формирующие положительный профессиональный имидж. Полученные данные доказывают влияние социального признания на формирование профессионального имиджа учителя, что способствует повышению статуса педагога. Результаты исследования вносят вклад в развитие теории социального признания в контексте педагогической науки, и могут быть использованы при построении кадровой политики образовательного учреждения.
\end{abstract}

Ключевые слова: социальное признание, профессиональный имидж учителя, потребность в интеграции, потребность в дифференциации, внутреннее социальное признание, внешнее социальное признание

Для цитирования: Шаруева Е.В. 2021. Социальное признание как фактор формирования профессионального имиджа учителя. Вопросы журналистики, педагогики и языкознания, 41 (1): 476-485. DOI: 10.52575/2712-7451-2021-40-4-476-485

\section{Social Recognition as a Factor in the Formation of the Professional Image of a Teacher}

\author{
Ekaterina V. Sharueva \\ Samara Branch Moscow City Pedagogical University, \\ 76 Stara Zagora St, Samara 443081, Russian Federation \\ E-mail: eb3011@mail.ru
}

\begin{abstract}
Currently, the education system imposes new requirements not only for the professional activities of the modern teacher, but also to his personality. Despite the fact that these requirements are aimed at modernizing the professional activities of a teacher, they introduce qualitative changes in his professional status as an employee of the educational sphere. The issue of raising the status of the teacher is a priority of modern educational policy. Thus, there is a contradiction between the state's need to raise
\end{abstract}


the status of the teacher and the limited social opportunities to form his positive professional image. Despite the large number of publications on the professional image of the teacher, social recognition as a factor in its formation has not been sufficiently studied. The purpose of this study - to confirm the hypothesis: the leading social factor that has a significant influence on the formation of the professional image of the teacher and reflects its social status, is the social recognition of its teaching activities by participants of educational relations and to identify the level and types of social recognition of professional teaching activities that form a professional image of the teacher and aimed at improving its professional status. The study was conducted on the basis of content analysis of regulatory documents governing the professional activities of teachers and analysis of the pedagogical staff of the Samara region. As a result of the study levels and types of social recognition of a representative of the teaching profession, aimed at improving the status of the teacher and forming a positive professional image were identified. The findings prove the impact of social recognition on the formation of professional image of the teacher, which contributes to the status of the teacher. The results of the study contribute to the development of the theory of social recognition in the context of pedagogical science, and can be used in building personnel policy of the educational institution.

Key words: social recognition, professional image of a teacher, the need for integration, the need for differentiation, internal social recognition, external social recognition

For citation: Sharueva E.V. 2021. Social Recognition as a Factor in the Formation of the Professional Image of a Teacher. Issues in Journalism, Education, Linguistics, 41 (1): 476-485 (in Russian). DOI: $10.52575 / 2712-7451-2021-40-4-476-485$

\section{Введение}

Масштабная программа РФ «Развитие образования до 2025 года» (от 26.12.2017 № 1642) направлена на модернизацию и развитие системы образования, совершенствование профессионализма педагогических работников. В современной образовательной системе профессиональное мастерство учителя выступает катализатором инноваций этой системы, определяет результативность и признание его профессиональных достижений участниками образовательных отношений.

Социальное признание играет ведущую роль в построении профессиональной деятельности современным учителем, поскольку педагогическая деятельность является отражением социальных ожиданий в обучении и воспитании нового поколения. Таким образом, в современном обществе профессиональная деятельность учителя не только реализует социальный запрос в отношении результатов образовательной деятельности, но и формирует стереотипы общественного восприятия педагогической профессии. Данные стереотипы опираются на потребности и ожидания, сложившиеся представления о профессиональной деятельности и личностных качествах учителя в социальном окружении и входят в структуру профессионального педагогического имиджа. Профессиональный имидж обеспечивает функциональную связь между профессиональными качествами и личностным развитием учителя, повышая конкурентоспособность субъекта в профессиональной среде, способствуя диверсификации образовательных услуг и вариативности содержания образования [Носков, 2016, с. 141].

Влияние признания профессиональной деятельности учителя как профессиональным, так и социальным сообществом на формирование профессионального имиджа выявлено многими исследователями. Так, Е.Б. Перелыгина отмечает, что имидж является «средством установления гармоничных отношений со своим социальным окружением» [Перелыгина, 2005]. Также социализирующую функцию имиджа выделяет С.К. Харбик, по ее мнению, имидж приобретает значение «в процессе социального, а не индивидуального восприятия объекта» [Харбих, 2015, с. 310]. К.А. Аржанова выделяет функционирование имиджа при формировании социальных представлений и мотивационной структуры 
индивида, закономерным результатом которого является проявление предсказуемых моделей поведения личности в ее социальной группе [Аржанова, Довжик, 2020, с. 158].

Опираясь на данные определения, профессиональный имидж может быть представлен как целенаправленно сформированный эмоционально окрашенный образ, базирующийся на совокупности индивидуально-личностных, социально-коммуникативных качествах и профессиональных характеристиках личности, обусловленных требованиями его профессионального и социального окружения.

Анализ определений профессионального имиджа учителя позволяет заключить, что социальное признание профессиональной деятельности учителя может выступать одним из факторов формирования его профессионального имиджа, где под фактором понимается «активный элемент воздействия» на данный процесс, определяющий его результат [Бусыгина, 2001, с. 124].

Таким образом, обзор теоретических исследований по формированию профессионального имиджа учителя, опирающихся на социальное признание как фактор его сформированности, показал, что категориальный аппарат данного феномена в педагогической науке не раскрыт полностью. Отсутствует четкое представление о видах и уровнях социального признания представителей педагогической профессии и их дифференциации. Все это усложняет работу по формированию положительного профессионального имиджа педагога, снижает эффективность влияния на повышение социального статуса представителя данной профессии.

Цель исследования - подтвердить гипотезу: ведущим социальным фактором, оказывающим значительное влияние на формирование профессионального имиджа учителя и отражающее его социальный статус, выступает социальное признание его педагогической деятельности участниками образовательных отношений, выявить уровень и виды социального признания профессиональной педагогической деятельности, формирующие профессиональный имидж учителя и направленные на повышение его социального статуса.

\section{Объекты и методы исследования}

Объект исследования - социальное признание профессиональной деятельности учителя. Специфика объекта исследования предопределяет использование теоретического анализа источников зарубежной и отечественной литературы, который позволил определить понятие социального признания.

Основным методом исследования выступает контент-анализ нормативно правовых документов, регламентирующих профессиональную деятельность учителя, позволяющий определить виды социального признания педагогической деятельности учителя.

Также был проведен анализ кадрового потенциала Самарской области с позиций: профессиональной квалификации, представленной уровнем образования и наличием квалификационной категории; опыта профессиональной деятельности; распространения педагогического опыта, наличия различных видов поощрения, а также признания профессиональных достижений органами власти.

Для репрезентативности полученных результатов был использован метод статистической и математической обработки данных, которые были получены в ходе исследования.

\section{Понятие и уровни социального признания}

В научной литературе социальное признание широко представлено прежде всего в психологических исследованиях, где под данной категорией понимают устойчивую, как правило, высокую оценку достоинств индивида обществом, порождающую уважение окружающих и способствующую повышению мотивации и самооценки личности [Myers, DeWall, 2018; Еникеев, 2019]. 
В социологических исследованиях социальное признание трактуется как положительная оценка индивида окружающими, являющаяся одним из важнейших мотивов человеческой деятельности, способствующей стабильности социальных отношений [Журавлев и др., 2019].

Более широкое распространение в настоящее время феномен социального признания получил в социальной психологии, где выделяется психологическая потребность индивида, имеющего социальное окружение, в социальном признании. В данном подходе исследователи выделяют два типа социального признания, базирующихся на потребности индивида в интеграции в социальное окружение и потребности в социальной дифференциации.

Потребность в интеграции является более сильной потребностью индивида, основанной на стремлении соответствовать референтной группе, к которой он себя относит, подражая ценностям, идеям и образу жизни, принятому в ней [Наумцева, Климов, 2017]. Данная потребность присуща каждому человеку, живущему в социуме, являясь самым сильным импульсом его деятельности.

Потребность в дифференциации строится на потребности индивида занимать субъектную позицию по отношению к его социальному окружению для признания значимых характеристик личности, способствующих признанию ее индивидуальности [Li et al., 2018].

Потребность в интеграции и дифференциации личности заложена в концепции «отражения себя», которая описывает психологическое восприятие личности себя глазами других [He, Brown, 2013]. Человек определяет и видит себя так, как, по его мнению, его воспринимают и судят о нем другие. В то же время при самоопределении человек строит свою Я-концепцию, тем самым дифференцируя свои личностные качества [Crocetti et al., 2014]. Социализация личности строится на идентификации личности, старающейся подтвердить взгляд на свое групповое «я» через восприятие себя другими, тем самым создавая определенный образ, отвечающий ожиданиям целевой группы [Johnson et al., 2012].

Данная концепция социального признания входит в структуру и содержание профессионального имиджа, трактуя данное понятие через «эмоционально окрашенный стереотип восприятия образа педагога в сознании участников образовательного процесса и социального окружения...» [Гурчиани, 2010]. Также многие исследователи [Бусыгина 2001; Гурчиани, 2010] определяют данный феномен через социальный эмоциональноокрашенный образ, который формируется в процессе субъект-субъектного взаимодействия, символически закрепляя определенную информацию о субъекте [Бусыгина, 2001].

Данные определения подтверждают, что человек, относящий себя к какой-либо группе, старается донести свою групповую идентичность с помощью социально признанных символов, так же как личность, занимающая субъективную позицию, самосимволизируется для передачи личной идентичности [Бессережнева, Погодина, 2020], тем самым формируя свой профессиональный имидж как представителя педагогической профессии.

Социальное признание является важным компонентом удовлетворения потребности личности в общественном признании созданного образа, для реализации потребности в признании человек будет усердно работать над достижением идеального образа, соответствующего ожиданиям целевой группы, путем приобретения символов группы или попыток манипулировать взглядами других [Zhao et al., 2016].

Исходя из данной концепции социального признания, мы можем определить его как фактор формирования профессионального имиджа учителя. В процессе формирования профессионального имиджа социальное признание выступает катализатором данного процесса, определяя вектор его развития.

Опираясь на теорию потребности личности в интеграции и дифференциации в референтной группе, в социальном признании профессиональной деятельности учителя можно выделить два уровня: внутренний уровень, который строится на личностном профессионализме, соответствующем ожиданиям и стремлениям целевой группы и включа- 
ющем в себя желания и стремления, направленные на достижение компетентности и профессиональной уверенности в своей педагогической деятельности; внешний уровень социального признания учителя, который основан на дифференциации учителя в профессиональном окружении, базирующийся на потребности в завоевании репутации, престиже и статусе в своей профессиональной деятельности [Haslam et al., 2017].

Из этого следует, что внутренний уровень социального признания базируется на повышении профессиональной компетентности учителя, являющейся способностью специалиста решать определенный класс профессиональных задач и соответствовать формальным требованиям к личностным и профессиональным качествам сотрудников данной профессиональной сферы [Андриенко, 2018].

Внешний уровень социального признания выражен различными видами признания и поощрения профессиональной деятельности учителя, оказывающими непосредственное влияние на его профессиональное положение в социуме, как представителя педагогического труда.

\section{Виды социального признания}

В ходе проведенного контент-анализа нормативно-правовых документов, регламентирующих профессиональную деятельность учителя (Закона «Об образовании в Самарской области» от 22.12.2014 № 133-ГД; Федерального государственного образовательного стандарта среднего общего образования; профессионального стандарта «Педагог» национальной системы учительского роста (НСУР) [Об утверждении... 2010; Об утверждении... 2013; Комплексная программа... 2014; Об образовании... 2014]) были выявлены следующие виды социального признания представителя педагогической профессии:

- профессиональная квалификация, которая характеризуется уровнем профессионального образования и наличием квалификационной категории, представлена в 4 из 4 исследованных документов;

- опыт профессиональной деятельности как показатель ее эффективности встречается в 3 из 4 вышеуказанных документов;

- распространение профессионального опыта, выраженное в участии в различных конференциях и конкурсах профессионального мастерства, представлено в 2 документах;

- различные виды поощрения и признание профессиональных достижений органами власти встречается в 2 исследованных документах.

Данные виды социального признания профессиональной деятельности учителя были рассмотрены более конкретно на примере педагогического кадрового потенциала Самарской области.

В общеобразовательных организациях Самарской области на конец 2020 года работало 19676 учителей. Современные образовательные стандарты регламентируют наличие высшего профессионального образования у каждого учителя, тем самым определяя его социальное признание не только в профессиональном сообществе, но и в социальном окружении.

Анализ уровня образования педагогов в 2020 году показал, что 89 \% педагогических работников имеют высшее образование, в том числе $62,1 \%$ от общего количества имеют профильное высшее образование, в то время как 26,9 \% прошли профессиональную переподготовку по педагогическому направлению; 11 \% учителей имеют среднее профессиональное образование. Данные показатели свидетельствуют о высоком уровне педагогического кадрового потенциала региона, который, тем не менее, находится на среднем уровне по стране, но позволяет реализовывать образовательную политику в полном объеме, что способствует не только внутреннему, но и внешнему социальному при- 
знанию учителей, а значит, и формированию положительного имиджа представителей педагогической профессии в регионе.

Одним из показателей внутреннего социального признания педагога является наличие квалификационной категории. Квалификационная категория учителя является фактом профессиональной оценки и социального признания его педагогической деятельности. Профессиональная аттестация направлена на непрерывное развитие учителя, позволяя корректировать свою профессиональную деятельность с учетом запроса участников образовательных отношений и демонстрировать ее результативность согласно предъявляемым требованиям к педагогической деятельности. В результате аттестации учителю присваивается первая или высшая квалификационная категория сроком на пять лет, дифференцирующая уровень оплаты педагогического труда, тем самым повышая профессиональный статус педагогического работника.

Анализ профессиональной квалификации учителей Самарской области в 2020 году показал, что 2681 педагог проходил профессиональную аттестацию, в результате которой 1188 учителям была присвоена первая квалификационная категории и 1385 высшая. С целью повышения профессиональной компетентности педагогических кадров в Самарской области с 2006 года действует система именного образовательного чека, согласно которому учитель каждые три года должен проходить курсы повышения квалификации в объеме 108 часов, что также учитывается при аттестации.

Данные аттестации учителей за 2020 год свидетельствует о высоком уровне квалификации педагогов и их социальном признании в профессиональном сообществе, что способствует становлению положительного профессионального имиджа учителя.

Также показателем компетентности учителя выступает опыт его профессиональной деятельности, который представлен педагогическим стажем, характеризующим результативность образовательной деятельности педагога.

Анализ педагогических кадров Самарской области демонстрирует, что 64,1 \% учителей имеют стаж профессиональной деятельности 15 лет и более, что способствует весомости профессиональных достижений, отражающихся в его социальном признании, повышая статус учителя. Поэтому стаж профессиональной деятельности учителя позволяет педагогу получать признание своих достижений не только в профессиональном сообществе, но и в социальном окружении.

Внешним уровнем социального признания выступают различные виды поощрений и признаний представителей педагогической профессии, к которым относятся: государственные награды, ведомственные отраслевые награды, почетные звания, такие как «Заслуженный учитель РФ», «Почетный работник образования», «Ветеран труда».

Анализ педагогического кадрового потенциала Самарской области в 2020 году показал, что 0,16 \% учителей имеют государственные награды; 21,3 \% учителей присуждены ведомственные награды Минобрнауки и Минпросвещения РФ; 13,9 \% награждены почетной грамотой Минобрнауки РФ.

Один педагог Самарской области имеет звание народный учитель СССР; 0,3 \% педагогов удостоены почетного звания «Заслуженный учитель РФ»; 12,8 \% педагогов имеют звание «Почетный работник образования»; 2,4% являются «Ветеранами труда».

Еще одним видом социального признания профессиональной деятельности учителя является «Конкурс на присуждение премий лучшим учителям за достижения в педагогической деятельности», проходящий во всех регионах России с 2007 года. В рамках реализации Указа Президента РФ от 28 января 2010 года «О денежном поощрении лучших учителей», учителям, добившимся внушительных результатов в своей профессиональной деятельности и сумевшим презентовать результаты своей работы, выплачивается премия в размере 200 тысяч рублей.

Внешним уровнем социального признания профессиональной деятельности учителя выступает трансляция педагогического опыта и участие в конкурсах профессионально- 
го мастерства. Показательность профессиональных достижений способствует позитивной оценке профессиональной деятельности учителя, основанной на восприятии педагога участниками образовательного процесса и признании его достоинств не только как специалиста, но и как личности.

Одним из наиболее значимых конкурсов профессионального мастерства является всероссийский ежегодный конкурс «Учитель года России», который проводится с 1992 года с целью поддержки и поощрения передовых педагогических практик школьных учителей. Данный конкурс проводится в каждом регионе, способствуя повышению статуса педагогических работников, т. к. лауреатов и финалистов регионального этапа поощряют денежными вознаграждениями, а с 2011 года в Самарской области победитель награждается автомобилем LADA. В результате регионального этапа отбираются 60 финалистов конкурса для участия во всероссийском этапе конкурса. Финал проходит в несколько этапов, где по итогам первого этапа отбирают 15 лауреатов, второго - 5 финалистов и по сумме балов двух заключительных этапов выявляют победителя конкурса.

В заключительном этапе Всероссийского конкурса «Учитель года России» с 2000 по 2021 гг. участвовал 21 педагог Самарской области. Из них финалистами стали 17 учителей, 4 педагога стали призерами и один - абсолютным победителем.

В Самарской области с 2008 года проводится областная общественная акция «Народное признание», призванная определить достойных жителей региона, достигших значительных успехов в профессиональной или общественной деятельности. Педагоги Самарской области являются постоянными участниками данной акции, которая определяет победителей общественного голосования по номинациям. За 2008 -2020 года лауреатами были признаны 34 представителя педагогической профессии в номинациях: «Признание и уважение», «Признание и мастерство», «Гордость и слава», «Честь и доблесть», «Имя года», «Открытие года», «Открытие и созидание», «За верность земле», «Рожденные в сердце России», «Дружба и братство», «Комсомол - моя судьба», «Память и слава».

Рассмотренные виды социального признания представителей педагогической профессии, достаточно широко представленные в Самарской области, не исключают других вариантов общественного признание учителей.

Социальное признание заслуг педагога в профессиональной деятельности на федеральном или региональном уровне стимулирует педагогов к профессиональноличностному развитию и позволяет определить факторы, формирующие профессиональный имидж как представителя педагогического труда, так и профессии в целом.

\section{Заключение}

В ходе данного исследования авторы уточнили понятие социального признания, которое выражается в положительной оценке индивида обществом, формирующей мотивацию личности в профессиональной деятельности, что способствует стабильности социальных и профессиональных отношений.

В нормативных документах отражаются такие виды социального признания, как профессиональная квалификация, характеризующаяся уровнем профессионального образования и наличием квалификационной категории; опыт профессиональной деятельности; распространение профессионального опыта, выраженное в участии в различных конференциях и конкурсах профессионального мастерства; различные виды поощрения и признание профессиональных достижений органами власти.

Анализ данного феномена в теоретическом аспекте позволил интегрировать внешний и внутренний уровни социального признания в педагогическую науку на основе социального признания представителей педагогической профессии и конкретизировать данный феномен педагогическими категориями.

К внутреннему уровню социального признания учителя относятся: уровень профессионального образования, наличие квалификационной категории, стаж педагогической 
деятельности, которые отражают личностный профессионализм, соответствующий ожиданиям и стремлениям целевой группы.

Внешний уровень социального признания включает в себя распространение профессионального опыта, выраженное в участии в различных конференциях и конкурсах профессионального мастерства; различные виды поощрения и признание профессиональных достижений органами власти; социальную активность педагога, что способствует дифференциации каждого учителя в профессиональном и социальном окружении.

Анализ видов социального признания представителей педагогической профессии на примере кадрового потенциала Самарской области подтверждает выдвинутую гипотезу, что социальное признание является фактором формирования профессионального имиджа учителя, способствует развитию не только отдельных структурных компонентов данного феномена, но и формированию идеального образа представителя педагогического труда в обществе, тем самым повышая социальный статус учителя.

Данное исследование позволило конкретизировать категориальный аппарат феномена социальное признание с педагогического подхода, дифференцируя его по уровням и видам, которые способствуют формированию положительного профессионального имиджа учителя, что ведет к повышению статуса представителя данной профессии.

Полученные результаты исследования могут быть использованы в формировании системы профессионального продвижения педагогических кадров и повышения их социального статуса на основе имиджформирующих факторов.

\section{Список источников}

1. Андриенко Е.В. 2018. Социальная психология. М., Academia, 320 с.

2. Об образовании в Самарской области. Закон Самарской области от 22 декабря 2014 г. № 133-ГД. URL: https://pravo.samregion.ru/zakony/zakon-samarskoj-oblasti-ot-22-12-2014-133-gd-obobrazovanii-v-samarskoj-oblasti/ (дата обращения: 10.08.2021).

3. Еникеев М.И. 2019. Общая и социальная психология. Москва, Норма, 224 с.

4. Журавлев А.Л., Позняков В.П., Резников Е.Н., Рощин С.К., Соснин В.А., Хащенко В.А., Шорохова Е.В. 2019. Социальная психология. Под ред. А. Л. Журавлева. Москва, Саратов, ПЕР СЭ, Ай Пи Эр Медиа, 351 с.

5. Комплексная программа повышения профессионального уровня педагогических работников общеобразовательных организаций. Правительство РФ от 28 мая 2014 г. № 3241п-П8. URL: https://www.garant.ru/products/ipo/prime/doc/70616270/ (дата обращения: 10.10.2021).

6. Об утверждении профессионального стандарта «Педагог (педагогическая деятельность в сфере дошкольного, начального общего, основного общего, среднего общего образования) (воспитатель, учитель)». Приказ Минтруда России от 18 октября 2013 г. № 544н. URL: http://www.rosmintrud. ru/docs/mintrud/orders/129 (дата обращения: 03.10.2021).

7. Об утверждении федерального государственного образовательного стандарта основного общего образования (с изменениями от 11 декабря 2020 г.). Приказ Министерства образования и науки Российской Федерации от 17 декабря 2010 г. № 1897. URL: https://docs.cntd.ru/document/902254916 (дата обращения: 10.09.2021).

\section{Список литературы}

1. Аржанова К.А., Довжик Г.В. 2020. Специфика восприятия имиджей профессий по рекламе и связям с общественностью. Вестник ГУУ, 10: 157-162. DOI: 10.26425/1816-4277-2020$10-157-162$

2. Бессережнева С.А., Погодина А.В. 2020. Проблема профессиональной адаптации молодых специалистов в современных организациях: социально-психологический аспект. В кн.: Социальная психология: вопросы теории и практики. Материалы V Всероссийской научнопрактической конференции с международным участием памяти М.Ю. Кондратьева, г. Москва, 12 13 мая 2020 г. Москва, ФГБОУ ВО МГППУ: 78-81.

3. Бусыгина Т.А. 2001. Имидж как фактор успешности в карьере. В кн.: Проблемы развития предприятий: экономика, организация, менеджмент. Материалы 1-й Международной 
научно-практической конференции, г. Самара, 24-25 апреля 2001 г. Под ред. А.П. Жабина, Е.В. Заровой. Самара, Изд-во СГЭУ: 123-125.

4. Гурчиани К.С. 2010. Психологический анализ имиджа. Вестник Ярославского государственного университета им. П.Г. Демидова. Серия: Гуманитарные науки, 1(11): 63-67.

5. Наумцева Е.А., Климов А.А. 2017. Взаимосвязь психологической готовности к организационным изменениям и организационной идентификации. Вектор науки Тольяттинского государственного университета. Серия: Педагогика, психология, 3 (30): 71-75. DOI: $10.18323 / 2221-5662-2017-3-71-75$

6. Несмеянова Р.К. 2018. Связь социально-демографических характеристик сотрудников с их организационной идентификацией и привлекательностью для них корпоративной культуры. Социальная психология и общество, 9 (1): 67-77. DOI:10.17759/sps.2018090105

7. Носков И.А. 2016. Имидж в маркетинговой стратегии развития образования. В кн.: Высшее гуманитарное образование XXI века: проблемы и перспективы. Материалы одиннадцатой международной научно-практической конференции, г. Самара, 28-29 сентября 2016 года. Под ред. Л.В. Вершининой. Самара, СГСПУ: 139-143.

8. Перелыгина Е.Б. 2005. Восприятие и изменение имиджа как феномена интерсубъектного взаимодействия. Российский психологический журнал, 2 (2): 26-43. DOI: https://doi.org/10.21702/rpj.2005.2.4

9. Сидоренков А.В., Шипитько О.Ю., Штильников Д.Е., Штроо В.А. 2019. Разработка инструментария изучения идентификации работников в организации. Организационная психология, 9 (3): 74-102.

10. Харбих С.К. 2015. Международный имидж государства. Факторы формирования. Социально-гуманитарные знания, 2: 308-314.

11. Crocetti E., Avanzi L., Hawk S., Fraccaroli F., Meeus W. 2014. Personal and social facets of job identity: A person-centered approach. Journal of Business \& Psychology, 29 (2): 281-300. DOI: 10.1007/s10869-013-9313-x

12. Haslam S.A., Cornelissen J.P., Werner M.D. 2017. Metatheories and Metaphors of Organizational Identity: Integrating Social Constructionist, Social Identity, and Social Actor Perspectives within a Social Interactionist Model. International Journal of Management Reviews, 19 (3): 318-336. DOI: $10.1111 /$ ijmr.12150

13. He H., Brown A.D. 2013. Organizational identity and organizational identification: A review of the literature and suggestions for future research. Group \& Organization Management, 38 (1): 3-35. DOI: https://doi.org/10.1177/1059601112473815

14. Johnson M.D., Morgeson F.P., Hekman D.R. 2012. Cognitive and affective identification: Exploring the links between different forms of social identification and personality with work attitudes and behavior. Journal of Organizational Behavior, $33(8)$ : 1142-1167. DOI: https://doi.org/10.1002/job.1787

15. Li J., Furst-Holloway S., Masterson S.S., Gales L.M., Blume B.D. 2018. Leader-member exchange and leader identification: Comparison and integration. Journal of Managerial Psychology, 33 (2): 122-141. DOI: 10.1108/JMP-06-2017-0220

16. Myers D., DeWall C. 2018. Psychology. New York, Worth Publishers, 896 p.

17. Zhao C., Liu Y., Gao Z. 2016. An identification perspective of servant leadership's effects. Journal of Managerial Psychology, 31 (5): 898-913. DOI: 10.1108/JMP-08-2014-0250

\section{References}

1. Arzhanova K.A., Dovzhik G.V. 2020. Specifics of perception of images of professions in advertising and public relations. Vestnik GUU, 10: 157-162 (in Russian). DOI: 10.26425/1816-42772020-10-157-162

2. Besserezhneva S.A., Pogodina A.V. 2020. Problema professional'noy adaptatsii molodykh spetsialistov $\mathrm{v}$ sovremennykh organizatsiyakh: sotsial'no-psikhologicheskiy aspect [The problem of professional adaptation of young specialists in modern organizations: socio-psychological aspect]. In: Sotsial'naya psikhologiya: voprosy teorii i praktiki [Social psychology: questions of theory and practice]. Materials of the V All-Russian Scientific and Practical Conference with international participation in memory of M.Y. Kondratiev, Moscow, May 12-13, 2020. M., Publ. FGBOU VO MGPPU: 78-81.

3. Busygina T.A. 2001. Imidzh kak faktor uspeshnosti v kar'ere [Image as a factor in career success]. In: Problemy razvitiya predpriyatiy: ekonomika, organizatsiya, menedzhment [Problems of 
enterprise development: economics, organization, management]. Materials of the 1st International Scientific and Practical Conference, Samara, April 24-25, 2001. Eds. A.P. Zhabin, E.V. Zarova. Samara, Publ. SGEU: 123-125.

4. Gurchiani K.S. 2010. Psychological analysis of image. Vestnik Yaroslavskogo gosudarstvennogo universiteta im. P. G. Demidova. Ser. Gumanitarnye nauki, 1 (11): 63-67 (in Russian).

5. Naumtseva E.A., Klimov A.A. 2017. The interrelation of psychological readiness to the organizational changes and organizational identification. Science vector of Togliatti state university. Series: pedagogy, psychology, 3(30): 71-75 (in Russian). DOI: 10.18323/2221-5662-2017-3-71-75.

6. Nesmeyanova R.K. 2018. The relationship between the socio-demographic characteristics of employees and their organizational identification and their perceived attractiveness of corporate culture. Social Psychology and Society, 9 (1): 67-77 (in Russian). DOI:10.17759/sps.2018090105.

7. Noskov I.A. 2016. Imidzh v marketingovoy strategii razvitiya obrazovaniya [Image in the marketing strategy of education development]. In: Vysshee gumanitarnoe obrazovanie XXI veka: problemy i perspektivy [Higher education in the humanities of the XXI century: problems and prospects]. Materials of the eleventh International Scientific and Practical Conference, Samara, September 28-29, 2016. Ed. L.V. Vershinina. Samara, Publ. SGSPU: 139-143.

8. Perelygina E.B. 2005. Perception and change of image as a phenomenon of interpersonal relationship. Russian psychological journal, 2 (2): 26-43 (in Russian). DOI: https://doi.org/ 10.21702/rpj.2005.2.4

9. Sidorenkov A.V., Shipit'ko O.Yu., Shtil'nikov D.E., Shtroo V.A. 2019. Development of tools for the study of employee identity in the organization. Organizational Psychology, 9 (3): 74-102 (in Russian).

10. Kharbikh S.K. 2015. International image of the state. Sotsial'no-gumanitarnye znaniya, 2: 308-314 (in Russian).

11. Crocetti E., Avanzi L., Hawk S., Fraccaroli F., Meeus W. 2014. Personal and social facets of job identity: A person-centered approach. Journal of Business \& Psychology, 29(2): 281-300. DOI: 10.1007/s10869-013-9313-x

12. Haslam S.A., Cornelissen J.P., Werner M.D. 2017. Metatheories and Metaphors of Organizational Identity: Integrating Social Constructionist, Social Identity, and Social Actor Perspectives within a Social Interactionist Model. International Journal of Management Reviews, 19(3): 318-336. DOI: $10.1111 /$ ijmr.12150

13. He H., Brown A.D. 2013. Organizational identity and organizational identification: A review of the literature and suggestions for future research. Group \& Organization Management, 38(1): 3-35. DOI: https://doi.org/10.1177/1059601112473815

14. Johnson M.D., Morgeson F.P., Hekman D.R. 2012. Cognitive and affective identification: Exploring the links between different forms of social identification and personality with work attitudes and behavior. Journal of Organizational Behavior, 33(8): 1142-1167. DOI: https://doi.org/10.1002/job.1787

15. Li J., Furst-Holloway S., Masterson S.S., Gales L.M., Blume B.D. 2018. Leader-member exchange and leader identification: Comparison and integration. Journal of Managerial Psychology, 33(2): 122-141. DOI: 10.1108/JMP-06-2017-0220

16. Myers D., DeWall C. 2018. Psychology. New York, Worth Publishers, 896 p.

17. Zhao C., Liu Y., Gao Z. 2016. An identification perspective of servant leadership's effects. Journal of Managerial Psychology, 31(5): 898-913. DOI: 10.1108/JMP-08-2014-0250

Конфликт интересов: о потенциальном конфликте интересов не сообщалось.

Conflict of interest: no potential conflict of interest related to this article was reported.

\section{ИНФОРМАЦИЯ ОБ АВТОРЕ}

Шаруева Екатерина Викторовна, ассистент кафедры педагогики Самарского филиала Московского городского педагогического университета, г. Самара, Россия

\section{INFORMATION ABOUT THE AUTHOR}

Ekaterina V. Sharueva, assistant of the Department of Pedagogy of the Samara Branch of the Moscow City Pedagogical University, Samara, Russia 